IJ§ER

ISSN: 2149-5939
International Journal of Social Sciences and Education Research

Online, http://dergipark.gov.tr/ijsser

Volume: 3(2), 2017

\title{
Proaktif ve reaktif kriz iletişiminde alışveriş merkezlerinin iletişim stratejileri
}

\section{The communication strategies of shopping centers in proactive and reactive crisis communication}

\author{
Yeliz Kuşay ${ }^{1}$
}

\begin{abstract}
Received Date: $01 / 09$ / 2016
Accepted Date: 15 / $01 / 2017$

$\ddot{O} z$

Kurumların varlığını tehdit eden gelecekleri konusunda olumsuz etkiler yaratabilen krizler, yürütülecek başarılı kriz iletişim stratejileri sayesinde atlatılabilmektedir. Kriz iletişiminde olası kriz unsurlarının önceden öngörülmesi ve bunlara yönelik yol gösterici önlemlerin alınması kriz öncesi proaktif kriz iletişimi olarak tanımlanırken, krizin ortaya çıkması ile algıları etkilemek, imajı yeniden oluşturmak ya da pozitif yönde etkilemek için yürütülen çalışmalar reaktif kriz iletişimi olarak tanımlanmaktadır. Bu çalışma kapsamında halkın büyük bir çoğunluğunun, gerek sosyal bir aktivite gerekse, boş zaman değerlendirme ya da ĕglence amaçlı toplandiklart alışveriş merkezlerinin proaktif ve reaktif kriz iletişim stratejileri değerlendirmiştir. Alışveriş merkezlerinde (AVM) yaşanılabilecek olası krizlere yönelik izlenen kriz iletişim stratejileri irdelenmiştir. AVM yöneticileri ile yapılan görüşmede kriz durumlarına yönelik proaktif ve reaktif bir kriz iletişim stratejilerinin olup olmadı ğ l, nasıl bir iletişim stratejisi izledikleri sorgulanmıştır. Bu çalı̧̧manın amacı AVM yönetimlerinin olası krizlere yönelik kriz iletişim stratejilerinin neler olduğunu tespit etmektir. Günümüzde yaşanılan olumsuzluklar karşısında halkın güvenini sarsan ya da hayatını tehdit eden olumsuzluklara karşın AVM yönetimlerinin ne kadar bilinçli bir strateji izleyip izlemedikleri sorgulanmıştır. Buna bağlı olarak var olan tabloda yer alan eksiklikler ya da artılar saptanmıştır.
\end{abstract}

Anahtar sözcükler: Kriz, kriz iletişimi, proaktif kriz iletişimi, reaktif kriz iletişimi, alışveriş merkezleri

\begin{abstract}
The crisis that may threat the existence of the entities and lead to unfavorable impacts on their future can be overcome via successful crisis communication strategies. The foresight of the aspects of crisis in advance and taking leading precautions related to them have been described as pre-crisis proactive crisis communication when the reactive crisis communication is described as the studies on creating impacts on crisis perception, revitalizing the image or creating a positive impact on the image. Within the scope of this study, the shopping centers' proactive and reactive crisis communication strategies are going to be assessed as they represent the areas where most people usually gather with the purpose of either spending time on social and leisure activities or entertainment. The crisis communication strategies on possible crisis that may be experienced at Shopping Centers (SC) are going to be examined. During the interviews with SC managers, the inquiries related to whether they have a proactive and reactive crisis communication strategy and what kind of communication strategy they follow up. The purpose of this study is determining the crisis communication strategies of SC managements in case of possible crisis. How conscious strategies are followed by the SC managements against recently experienced unfavorable conditions that either betray peoples' trust or threaten their lives are going to be examined. Accordingly, both the existing relevant practices and improvement areas are going to be determined.
\end{abstract}

Keywords: Crisis, crisis communication, proactive crisis communication, reactive crisis communication, shopping centers

${ }^{1}$ Dr., Marmara Univ. Communication Faculty, Public Relations and Publicity Department, İSTANBUL/TURKEY, ykusay@marmara.edu.tr 
Kuşay, Y. (2017). Proaktif ve reaktif kriz iletişimininde alışveriş merkezlerinin iletişim stratejileri. International Journal of Social Sciences and Education Research, 3(2), 379-396.

\section{Giriş}

Beklenilmedik anlarda ortaya çıkan krizler, kurumların varlığını tehdit ederek, olumsuz imaj oluşmasına neden olmaktadır. Krizlerin olumsuz etkilerini azaltmaya ve çözüm odaklı stratejiler kriz yönetimi içerisinde değerlendirilir. Kriz yönetimi sürecinde hedef kitleleri bilgilendirmek, aydınlatmak ve ikna etmek için iletişime ihtiyaç vardır. Bu nedenle kriz yönetiminin işleyişi etkili bir kriz iletişimi sürecini de zorunlu kılar. İzlenecek proaktif ve reaktif kriz iletişim stratejileri bilgi akışının sağlanmasında ve belirsizliklerin ortadan kalkmasında önemli rol oynamaktadır. Proaktif kriz iletişimi, kriz unsurlarının önceden algılanması ve alınması gereken önlemleri içerirken, kriz sırası ve sonrası krize yönelik cevap stratejileri, reaktif kriz iletişim planını oluşturur.

Alışveriş ve eğlence ihtiyaçlarını karşılamak, sosyal ilişki kurmak, boş zaman değerlendirmek gibi nedenlerle yararlanılan alışveriş merkezleri (AVM), olası pek çok krizin meydana geldiği mekanlardır. Dolayısıyla AVM yönetimlerinin küresel rekabet düzeninde krizden en az zararla kurtulmak, krizleri firsata çevirebilmek adına izleyecekleri stratejiler kriz iletişiminin gerekliliğini ortaya koyar. Kriz iletişim stratejileri, kriz sonrası yaraları sararak, kuruma yönelik güvenin, olumlu imajın ve itibarın yeniden inşasında önemli rol oynar.

Çalı̧̧mada alışveriş merkezlerinin kriz iletişim stratejileri üzerinde durulmuştur. AVM yönetimlerinin proaktif ve reaktif kriz stratejilerini değerlendirmeyi amaçlayan çalışma kapsamında, İstanbul'da faaliyet gösteren ve rastgele örneklem yönetimiyle seçilen AVM'lerle görüşmeler yapılması hedeflenmiştir. Çalışma kapsamında görüşme talebine olumlu yanıt veren üç AVM’nin kriz stratejilerini belirlenen araştırma kriterlerine göre değerlendirilmiştir.

Çalışmada kriz iletişimi sürecinde yer alması gereken kriterler incelenecektir. Krize yönelik proaktif ya da reaktif kriz iletişim planının olup olmadığ 1 , kriz iletişimin ekibinin kimlerden oluştuğu, kriz durumunda kurum sözcüsünün kim olduğu, kriz iletişim sürecinde hangi aşamada hangi adımların atılacağını belirlemek üzere bir zaman tablosunun olup olmadığı, kriz iletişiminde hedef kitlelerle iletişimde kullanılan iletişim araçları ve kriz iletişim bütçesi, kriz öncesi, sırası ve sonrası aşamaları açısından sorgulanmıştır. AVM yönetimlerinin kriz durumunda krize sahip çıkma, açıklama yapma, gerekli durumlarda özür dileme, hedef kitlelerle çift yönlü iletişime geçme ve mesaj iletimlerinde kullanılan iletişim kanalları araştırma kapsamında irdelenmiştir.

\section{Kriz kavramı ve kriz yönetimi}

Kurumların önceden tahmin edemedikleri, hedef kitlelerinin sağlık, güvenlik, çevre, ekonomik sorunlar gibi önemli beklentilerini tehdit eden, bunun sonucunda kurumların performanslarını ciddi bir biçimde etkileyen, negatif sonuçların ortaya çıkmasına neden olan durumlara kriz denir (Coombs, 2007: 3). Kriz meydana geldiğinde krizin doğasını ve ilgili hedef kitlelerini bilmek önemlidir. Öncelikle kriz ile ilgili iddiaların ve şüphelerin neler olduğu sorgulanmalıdır. Krizin doğasına göre yaşanılan olumsuzluğun şiddeti belirlenmeli ve uygun bir müdahale geliştirilmelidir. $\mathrm{Bu}$ yüzden önceden potansiyel krizlere yönelik tahmini ve ihtiyati planlar hazırlanmalıdır. Kriz planları periyodik olarak gözden geçirilmeli ve gerekli düzenlemeler krizlerin doğasına göre yeniden şekillendirilmelidir (Benoit, 1997: 182). Krizlerin önlenmesi, en az zarar ile atlatılmas1, bazı durumlarda firsata dönüştürülmesi için önceden yapılan bütün bu uygulamalar kriz yönetim süreci içerisinde değerlendirilir.

Kriz yönetimleri, krizlerle mücadele etmek, güncel tehdit unsurlarını ve krizin negatif sonuçlarını hafifletmek ve önlemek için tasarlanmış bir dizi faktörden oluşur. Bu şekilde kurumları, 
Kuşay, Y. (2017). The communication strategies of shopping centers in proactive and reactive crisis communication. International Journal of Social Sciences and Education Research, 3(2), 379-396.

hedef kitleleri ve sektörü tehditlerden korumaya çalışır. Bunun için kriz yönetimleri önleyici tedbirler, hazırlık, karşılık ya da cevap verme ve yeniden gözden geçirme/düzenleme faktörlerinden oluşan acil hazırlık planları hazırlar (Coombs, 2007: 5). Krizlere yönelik hazırlanan bu planlar kurumların kendi fiziksel, sektörel ve hedef kitlelerinin demografik yapılarına göre farklı kriz yönetim stratejilerini gerekli kılar.

Kriz yönetim stratejilerinin belirlenmesinde kurum yönetim anlayışı her zaman önem taşır. Operasyonel anlamda hazırlanan kriz yönetim stratejileri, iletişimsel anlamda karşılığını her zaman bulamaz.

Kurum yönetim anlayışına sahip olan mekanlar arasında büyük alanlar, stadyumlar, gösteri merkezi gibi kamu mekanları da yer alır. Bu yerler etkinlik ve büyük toplulukların neden olabileceği günlük krizlere yatkındırlar. Bir etkinlik sürecinde her bir kamusal alan ve buradaki etkinlikler birbirinden farklı olabileceği için halkın güvenliğini sağlamada olası krizler mekandan mekana değişebilir. Bu yüzden pek çok kurum kriz öncesi plana sahiptir. Fakat planı yönlendiren argümanlar daha çok krize neden olacak operasyonel bir bakış açısına sahiptir. Bu planda bir kriz iletişim stratejisine her zaman odaklanılmaz (Craig ve diğerleri, 2006: 171). Kriz iletişim stratejisin olmaması, planlanan kriz yönetim süreçlerini olumsuz anlamda etkileyebilir. Belirsizliklerin yaşanması, hedef kitlelerle zamanında doğru bilgi akışının sağlanamaması, kurum itibarına etki edecek olan iletişim eksiklikleri, kriz yönetiminin operasyonel başarısına gölge düşürebilir.

\subsection{Kriz iletişiminin gerekliliği}

"Kriz” kavramının en temel özelliği belirsizlik içermesidir. Reynolds ve Seeger (2005: 50) kriz anında yürütülmesi gereken acil iletişim ihtiyacının, belirsizliği azaltmak için gerekli olduğuna, bu durumun hedef kitlenin zihninde genel bir yargının oluşmasında etkili olduğuna değinmiştir (Liu ve diğerleri, 2016: 480). Krizlerin kurumsal beklentilere engel olması hedef kitlelerin olumsuz etkilenmesine neden olurken, hedef kitleler ve kurum arasındaki ilişkileri zedeler. $\mathrm{Bu}$ yüzden kurumsal itibar açısından krizler bir tehdit olarak düşünülmelidir. Kurumsal itibar hedef kitlelerin kurumu nasıl algıladığıdır. Hedef kitlenin beklentilerinin olumsuz yönde etkilenmeye başladığı aşamada kurum daha az pozitif algılanır. Kurumsal itibar zarara uğramaya başlar (Coombs, 2007: 4). İşte rekabet düzenin en hat safhada yaşandığ özellikle ticari kurumlara ev sahipliği yapan AVM'ler, kurumsal itibarlarına pozitif anlamda katkı sağlayacak yatırımlara ve uygulamalara imza atmalıdır. Özellikle kriz durumları bu anlamda kurumların en hassas hareket etmeleri gereken kriz iletişim sürecini gerektirir.

Hale ve diğerleri (2005) iletişimi kapsamayan bir kriz yönetimi ya da başarısız bir kriz iletişim stratejisindeki nedenleri şu şekilde tanımlar; kurum sitesinde yetersiz bilgi kaynaklarının oluşu, rutin ya da normal iletişim kanallarını kullanamama, tamamlanmamış kriz verileri ve/veya çelişkili yorumlamalar, yetersiz durumsal bilirkişi ve örgütsel tecrübeye dayanan mesaj filtreleri, alternatif araştırmanın önünü tıkayan zaman kısıtlamaları, bilgi yayılması ihtiyacıyla çelişen kaynaklar, hedef kitlenin beklentilerine cevap verememektedir. Loosemore (1998) ise etkili kriz iletişiminin uygulanabildiği zamanlarda krizin daha düşük olasılıkta olduğunu ortaya koyar. Sorumluluğun kimde olduğunun belirgin olmadı $\breve{g} 1$ durumlarda iletişimin önemi artan bir güç kaynağ haline gelir. (Ying ve Pheng, 2014:58). Belirsizliklerin yaşandığı, hedef kitlelerin algısının olumsuz anlamda etkilenebileceği kriz dönemleri, kriz iletişiminin önemini daha da vurgular.

Coombs \& Holladay (2002) kriz iletişimini, hedef kitlelerin durumu anlamasına yardımcı olacak bilgi olarak ifade eder. İletişimsel anlamda geliştirilen krize cevap stratejileri, tecrübelerden 
Kuşay, Y. (2017). Proaktif ve reaktif kriz iletişiminde alışveriş merkezlerinin iletişim stratejileri. International Journal of Social Sciences and Education Research, 3(2), 379-396.

ders çıkararak ve hedef kitlelerin fikirlerini harmanlayarak kurum imajını onarabilir, ya da itibar kaybını önleyebilir (Van Der Meer ve Verhoeven, 2014: 527).

\subsection{Proaktif ve reaktif kriz iletişim stratejisi}

Kriz iletişimi planı çoğunlukla reaktif tedbirler doğrultusunda uygulanırken, etkili halkla ilişkiler uzmanları proaktif bir kriz iletişim stratejisini benimser. Proaktif kriz iletişimi planında, kurum yöneticisi ve diğer ilgili yöneticiler ile iletişim, medya ile güçlü ilişkiler kurma, potansiyel var olan durumu takip etme, krizi dikkate alıp önemseme, kriz iletişimine yönelik becerileri geliştirme, kriz iletişim planını yeniden gözden geçirme ve kriz sonrasında kriz sonuçlarını takip etme gibi kriz yönetimi kapsamında önceden hazırlanmış bir iletişim planına sahip olmayı gerektirir (Whitt, 2014:22). Reaktif kriz iletişimi ise, krize hazırlıksız yakalanan, kriz öncesi iletişimsel bir stratejinin belirlenmediği, kriz sırası ve sonrası yapılacak iletişim sürecini ifade eder.

Jonathan Bernstein krizin etkilerini minimize etmek için bir kriz iletişimi yönetiminden bahseder. Bu süreç, kriz olmadan önce atılacak ilk adımdan kriz sonrası yapılacaklara kadar olan süreci kapsar. Buna göre; (Bernstein, 21.10.2016)

1. Öngörülebilir krizler / Kriz İletişim Planı: Kriz öncesi proaktif bir kriz iletişimi olarak kriz iletişim ekibi ile birlikte olası bütün krizlere yönelik yoğun bir beyin fırtınası yapılır. Olası krizlerin belirlenmesi, bazı durumların krize dönüşmesini engelleme yahut en uygun kriz müdahalesini geliştirme konusunda yararlı olur. Bu süreç operasyonel ve iletişim öğeleri aynı anda kapsar.

2. Kriz İletişim Ekibi Oluşturma: Kuruma kriz iletişim ekibi olarak hizmet verecek küçük bir üst düzey yönetici ekibi belirlenir. Kurumun CEO'su ekibin baş danışmanı olarak halkla ilişkiler yöneticisi ve hukuk müşaviri ile birlikte kriz iletişimi ekibine başkanlık yapar. Gerek görüldüğünde kriz iletişimi konusunda ajans veya bağımsız danışman desteği de alınabilir. Aynı zamanda bu ekip içerisinde konu ile ilgili özel bilgiye sahip uzmanların yer alması da gerekir.

3. Kriz Sözcüsünün Belirlenmesi: Kriz sürecinde önemli olan yetkili sözcülerin konuşmasıdır. Her kriz iletişim ekibinde eğitilmiş kişilerden oluşan, farklı iletişim kanalları için öncü ya da yedek sözcüler olmalıdır. Kriz sözcülerinin konuşma konusunda hitabetlerinin güçlü olması, aynı zamanda yazılı metin içeriklerinin de doğru ve düzgün bir dille ifadesi önemlidir. Kriz sözcüsü konumunda, kurum yöneticisine alternatif, uygun diğer pozisyonlardan da sözcü seçilebilir. Bu kişilerin gerekli eğitim ve bilgi donanıma sahip olması gerekir. Krizin doğasına göre hangi sözcünün görev alması gerektiği kriz anında netlik kazanır.

4. Kriz Sözcüsünün Eğitimi / Kitle İletişim Araçlarının Kullanımı: Hedef kitlelerin tepkilerini uygun hale getirmek için hazırlık yapmak gerekir. Bunun için hangi medya ya da hedef kitle ile nasıl konuşulacağı konusunda profesyonel eğitime ihtiyaç vardır.

5. Bildirim ve İzleme Sistemleri Oluşturma: Kriz iletişimine yönelik bildirim ve izleme sistemleri hedef kitle ile iletişimde önem taşır. Kriz öncesi hedef kitlelerle telefon, fax, e-posta, sms, sosyal medya hesapları ve platformları sayesinde hızl bir bildirim sistemi kurulmalıdır. Aynı zamanda izleme sistemleri sayesinde krizi önleme ve kriz tepkileri hakkında bilgi toplanır. Ücretli ve ücretsiz olarak hizmet sunan pek çok izleme sistemleri ve sonuç raporlama sistemleri vardır. Bu sayede kriz iletişim ekibine bilgi sağlayan bu sistemler hedef kitlelerin nabzını tutmaya yardım eder. 
Kuşay, Y. (2017). The communication strategies of shopping centers in proactive and reactive crisis communication. International Journal of Social Sciences and Education Research, 3(2), 379-396.

6. Hedef Kitleleri Belirleme: Kurumun iç ve dış hedef kitleleri belirlenir. Kurum çalışanlarının en önemli hedef kitle grubunda olduğu unutulmamalıdır. Çünkü çalışanlar bir kurumun halkla ilişkiler sorumlusu ya da kriz yöneticisi olarak dışarıda birer temsilcidir.

7. Kurum Bildirisi Hazırlama: Kriz öncesi, olası kriz senaryolarına yönelik, tam metin içerikleri hazırlanır. Kriz iletişim ekibi tarafından metinlerin revizyona ihtiyacı olup olmadığı ve diğer senaryolara ilişkin mesajların kontrolü sağlanmalıdır.

8. Krizin Değerlendirilmesi: Kriz iletişim ekibinden gelen bilgiler doğrultusunda krizin yapısına göre önceden hazırlanmış bir iletişim planı söz konusu ise en uygun cevap ile kısa sürede krize müdahale edilir. Aksi bir durumda 1-7 madde arasındaki kriterler çalışanlar ve kurum yöneticileri arasında hızlı bir şekilde geliştirilmelidir (reaktif iletişim planı). Elbette ki acele oluşturulan bir kriz iletişim stratejisi ve ekip çalışması, önceden planlanan ve prova edilen bir kriz iletişimine göre daha fazla hatayı barındıracaktır.

9. Anahtar Mesajlar Belirleme: Kriz iletişim ekibi hedef kitlelerin yapısına göre krize özgü mesajlar geliştirmelidir. Bu mesajların içerikleri ve şekli kullanılacak iletişim aracına uygun şekilde uyarlanmalıdır.

10. Kriz Sonrası Analiz: Kriz iletişim ekibi, kriz sürecinde neyin yanlış yapıldığını, eksiklik ve hataların telafi edilmesi, sonraki uygulamalarda daha başarılı bir kriz iletişim planının yapılması için krize karşı hazırlığın çeşitli unsurlarının nasıl geliştirileceğine yönelik bir analiz yapar. Bu çabalar gelecekte yaşanılacak olası krizlere karşın kurumlara daha hızlı ve daha doğru hareket etme konusunda olumlu anlamda katkı sağlayacaktır.

\subsection{Kriz iletişiminde hedef kitle, kitle iletişim araçları ve mesajın önemi}

Kriz durumlarında kurum itibarı açısından hedef kitlelerle (kurum yöneticileri, çalışanlar, müşteriler, mağdur ve mağdur yakınları, medya) iletişim önem taşır.

Yapılan bazı araştırmalar kriz öncesinde iyi bir itibara sahip, medya ile iyi ilişkileri olan kurumların daha az sorun yaşadıklarını, durumu uygun bir şekilde itiraf ettiklerini ortaya koyar (Stoff, 2007:21). Aynı zamanda Coombs \& Holladay’a (2008) göre, kriz mağdurlarının ihtiyaçlarına karşılık vermek ve kamu algısı oluşturmak için kurumun kriz sorumluluğunu üstlenmesi gerekir. Mağdurların zararının telafi edilmesi, samimi, içten bir iletişimin sergilenmesi özür dilemek ile benzer etkiye sahip olacaktır (Kiambi ve Shafer, 2016:133). Kurumun bu anlamda samimi ilişki sergilemesi konuya olan ilgi ve alakası, krizden kaynaklı mağduriyetleri gidermek için sundukları maddi ve manevi desteklerin hedef kitle ile paylaşımı kriz iletişimi stratejilerine bağlıdır.

Kriz yönetimi ve kriz iletişimi sürecinde yüz yüze iletişim, telefon, görsel ve işitsel iletişim araçlarının yanı sıra internet ve internet uygulamaları da iletişimin sürdürülmesinde önemli bir rol oynar. Kurumun websitesi, tartışma forumları, bloglar, sohbet odaları, Facebook, Twitter, Instagram gibi sosyal ağ siteleri kriz durumlarında anlık şekilde bilginin doğru ya da yanlış içeriklerle geniş kitlelere ulaşımında güç sahibidir. Bu ortamlarda kullanıcıların birbirleri ile olan etkileşimleri kriz açısından hem olumlu hem de olumsuz sonuçlar doğurabilir. Özellikle kriz iletişim sürecinde bu ortamların bilinçli ve stratejik olarak kullanılması iletişimde kolaylık sağlar.

Daha etkili iletişim kanalları geliştirmek için, sadece popüler bir çizgi yada söylenti boyutunun dışında, sosyal medya araçlarının özelliklerine göre iletişim stratejileri geliştirilmesi gerekir ( 
Kuşay, Y. (2017). Proaktif ve reaktif kriz iletişiminde alışveriş merkezlerinin iletişim stratejileri. International Journal of Social Sciences and Education Research, 3(2), 379-396.

Seyfi ve Güven, 2016: 272). Bu konuda kriz iletişimine yönelik, ağ yaklaşımı ile alanın uygulayıcıları ve akademi arasındaki işbirliği, uygulama sürümlü ve araştırma temelli stratejiler geliştirir. Krize cevap verme ve krizde çabuk iyileşme imkanı tanırken, kriz süresince bilginin hızlı bir şekilde yayılımında ve bilgi toplamada organizasyonel gücü artırır. (Stephens, Barrett,\&Mahometa, 2013'den aktaran Ford v.d., 2016: 331) Bu durum kriz iletişiminde iletişim araçlarının gücünü bir kez daha ortaya koymaktadır. Kriz iletişimi açısından krizlerin dinamik, ilişkili, karmaşık olan doğalarının ortaya konması iletişim ağı yaklaşımı ile gerek bilgi akışı gerekse esnek hareket edebilmek açısından kurumlara yön göstericidir. AVM yönetimlerinin ihmal ettikleri ya da korktukları büyük bir alan olan sosyal medya ortamları bu anlamda üzerinde durulması gereken önemli bir iletişim portalını oluşturur.

Kriz süresince kurumlar itibarları üzerindeki zararı engellemeye ve imajlarını onarmaya çalışır. Olumsuz yönde bir itibar değişimi, paydaşların kurumla etkileşime girme biçimini değiştirmesine sebep olacaktır. (Van der Meer ve Verhoeven, 2014: 526-527) Bundan dolayıdır ki kurumların krizden olumsuz anlamda etkilenmemesi için kriz iletişim sürecinde hedef kitlelere yönelik mesajların içeriği ile bilinçli bir şekilde hazırlanmalıdır.

Kriz yöneticisi, kriz mesaj stratejisini uygularken kriz yönetim stratejilerinin sinerjik sonuçlarına göre kriz planlarını oluşturmalıdır. (Kim ve diğerleri, 2009: 448) Dolayısıyla her bir kriz kendi içerisinde farklı dinamiklere sahip olacağından krize yönelik oluşturulacak stratejiler farklı kombinasyonları da içerebilir, tek model bir kriz yönetimi anlayışından ve tek bir kriz iletişimi stratejisinden bahsetmek doğru değildir.

Kriz iletişiminde iletilecek mesajlarda çift yönlü; interaktif bir iletişim anlayışının benimsenmesi, krize yönelik olumlu ve olumsuz detaylı ve açıklayıcı bilgi paylaşılması, şeffaf bir yapı sergilenmesi, krizin olumsuz etkileri nedeniyle özür dileme ya da krizin nedenleri, sonuçları ve telafisine ilişkin genel bir açıklama yapılması, krizin sahiplenilerek, zararın temini için gereken tüm sorumluluğun üstlenilmesi, tek seslilik ve aynı mesajın kurumun tüm iletişim kanalında yer alması değişmez kriz iletişim kriterlerini oluşturur (Akbayır ve Kuşay, 2015: 1181).

\section{3. İstanbul'daki Alışveriş Merkezlerinin proaktif ve reaktif iletişim stratejileri üzerine bir araştırma}

\subsection{Araştırmanin yöntemi}

$\mathrm{Bu}$ çalışmada kriz iletişimi ve alışveriş merkezleri konusundaki literatür taraması yapılmıştır. Elde edilen veriler doğrultusunda hazırlanan araştırma soruları AVM yetkililerine (AVM güvenlik müdürü, operasyon müdürü, kurumsal iletişim koordinatörü) yöneltilmiştir. İstanbul il sınırları içerisinde yer alan modern alıveriş merkezleri arasında, rastgele örneklem yöntemi ile seçilmiş üç AVM yönetimi ile görüşülmüştür. AVM yöneticileri ile proaktif ve reaktif kriz iletişim stratejileri konusunda görüşme 07 Ekim -28 Ekim 2016 tarihleri arasında yapılmıştır. Görüşme yapılan AVM'lerin yapısı bulundukları lokasyona ve ziyaretçi-hedef kitle profilleri göz önünde bulundurularak belirlenmiştir. Örneklemin oluşturulmasında her bir alışveriş merkezi için belli özellikler dikkate alınmıştır. Orta gelir seviyesine hitap eden AVM'ler arasında herkesin rahatça ulaşabileceği ve ortak nokta diye tanımlayabileceğimiz şehir içi bir alışveriş merkezi, sosyal eğlence içerikli ve açı alan konseptli bir AVM ve daha bölgesel anlamda çevre civardaki hedef kitlelere hitap eden diğer bir AVM araştırma kapsamında incelenmiştir. Görüşülen AVM'lerin güvenlik ve iletişim stratejilerinin gizliliği gereği ve talepleri doğrultusunda isimlerine yer verilmemiştir. 
Kuşay, Y. (2017). The communication strategies of shopping centers in proactive and reactive crisis communication. International Journal of Social Sciences and Education Research, 3(2), 379-396.

Bu nedenle araştırma kapsamında ele alınan AVM'ler AVM1, AVM2 ve AVM3 olarak kodlanmiştır.

\subsection{Araştırmanın amacl ve önemi}

Toplumsal yaşam alanı olarak alışveriş merkezleri gündelik hayatta oldukça yoğun kullanılan mekanlar arasında yer almaktadır. Bu mekanların bireyler tarafından tercih edilmeleri pek çok ihtiyacı karşılamaları ile paralellik göstermektedir. Rekabetin olduğu toplum düzeni içerisinde imaj, itibar, prestij ve algı yönetimi gibi konularda, hedef kitleler ile iletişimde, alışveriş merkezlerinin yönetim anlayışı önem kazanmaktadır. Alışveriş merkezlerinin bireysel imajlarının yanı sıra genel mekan başlığı altında alışveriş merkezi imajı olası krizler karşısında sarsılabilmektedir. Özellikle son zamanlarda haberlere yansıyan bomba ihbarı, intihar, hırsızlık gibi pek çok olumsuz haber, alışveriş merkezlerinin güvenliği ve benzeri konularda hedef kitlelerin zihninde şüphe uyandırabilmektedir. Var olan imajı ve güveni zedelemektedir. Bu nedenle çalışmanın amacı yaşanılan olumsuzluklar karşısında AVM yönetimlerinin izledikleri proaktif ve reaktif kriz iletişim stratejilerini tespit etmektir. Çalışma alışveriş merkezlerinin kriz iletişimi konusunda iletişim stratejilerinin güçlü ve zayıf yönlerini tespit etme açısından önem taşımaktadır.

\subsection{Araştırmanın kapsam ve sınırlılıkları}

Krizin ortaya çıkmasına neden olan teknolojik, hukuksal, politik, siyasi, sosyo-kültürel, psikolojik faktörlere bağlı olarak, AVM'lerde yaşanılan krizlerin, AVM yönetimleri tarafından nasıl yürütüldüğü araştırma kapsamında irdelenmektedir. AVM yönetimlerinin yaşadıkları krizler karşısında izledikleri kriz iletişim stratejileri içinde yer alan proaktif ve reaktif yaklaşımlar, teorisyenlerin altını çizdiği ideal kriz iletişim süreçleri açısından incelenmektedir.

Çalışma İstanbul il sınırları içerisindeki AVM'ler ile sınırlandırılmıştır. Kriz iletişim sürecinde söz sahibi olan AVM yetkilileri ile görüşülmüştür. AVM'lerin kriz durumunda iletişim anlamında nasıl bir strateji izledikleri yapılan görüşme ile tespit edilmiştir. AVM'lerin kriz iletişim anlayışları proaktif ve reaktif kriz iletişimi açısından değerlendirilmiştir.

Alışveriş merkezi yetkilileri ile yapılan yüz yüze görüşmede kriz iletişimi konusunda öncelikle kriz yönetimi planları olup olmadığı, bu plan dahilinde kriz iletişim planına yer verip vermedikleri sorgulanmıştır. Kriz iletişimi konusunda önceden hazırlık yapıp yapmadıkları öğrenilmeye çalışılmıştır. Sonuç olarak AVM'lerde yaşanılabilecek olası kriz süreçlerinde kriz iletişimini bilinçli bir şekilde yürütüp yürütmedikleri tespit edilmeye çalış1lmıştır.

Araştırmada AVM yetkililerine "kriz iletişim kriterleri" anlamında yönlendirilen soruların ana başlıkları; "Kriz İletişim Planı ,"Kriz İletişim Ekibi”, "Kriz Sözcüsü”, "Kriz İletişiminde Zaman Tablosu", "Kriz İletişiminde Kullanılan İletişim Araçları (mağdurlarla, çalışanlarla, ziyaretçiler ve medya ile iletişim)", "Kriz İletişim Bütçesi”nden oluşmaktadır.

Kriz iletişimi sürecinde hedef kitleye iletilen mesajların içerikleri ve bu mesajların nasıl iletildiğini tespit etmek için "Krize Sahip Çıkma”, "Açıklama Yapma - Özür dileme”, "Çift Yönlülük”, "Şeffaflık”, "Aynı mesajın kurumun tüm iletişim kanalında yer alması", "Sorulan soruları aynı iletişim kanalı üzerinden cevaplanması" kriterleri sorgulanmıştır. 
Kuşay, Y. (2017). Proaktif ve reaktif kriz iletişiminde alışveriş merkezlerinin iletişim stratejileri. International Journal of Social Sciences and Education Research, 3(2), 379-396.

\section{Bulgular}

Araştırmada AVM yetkilileri ile yapılan görüşmede AVM'lerin fiziksel özelliklerine bağlı olarak, yaşanma olasılı̆̆ yüksek olan hırsızlık, elektrik kesintisi, güvenlik zafiyeti, besin zehirlenmesi, personel krizleri, yangın ihbarı gibi krizlerin yanı sıra alışveriş merkezlerinin bulunduğu lokasyona ve bölge halkı ya da ziyaretçi profillerinin demografik yapısına göre siyasi grup etkinlikleri, ses ve sis bombası, kurşunlama, intihar, yasadışı terör örgütlerine tepki gösterisi, banka soygunu, yaralama ve adam öldürme, çocuk unutma \& kaybetme gibi krizlerin yaşandığı belirtilmiştir.

AVM yönetimlerinin kriz iletişim planı kriterlerine Tablo1'de yer verilmiştir. Tablo 2'de ise kriz iletişiminde alıveriş merkezlerinin ileti içerik özelliği ve iletilerin hedef kitlelere nasıl ulaştırıldığı tablolaştırılmıştır.

Tablo 1. Kriz iletişimi kriterleri

\begin{tabular}{|c|c|c|c|}
\hline \multicolumn{4}{|c|}{ Kriz iletisimi kriterleri } \\
\hline & AVM1 & AVM2 & AVM3 \\
\hline $\begin{array}{l}\text { Proaktif \& Reaktif } \\
\text { Kriz İletişim Planı }\end{array}$ & $\begin{array}{l}\text { Operasyonel anlamda proak- } \\
\text { tif bir kriz yönetim planı, re- } \\
\text { aktif yürüten bir iletişim } \\
\text { planı }\end{array}$ & $\begin{array}{l}\text { Reaktif bir kriz iletişim } \\
\text { planı }\end{array}$ & $\begin{array}{l}\text { Fiziksel şartlara uygun } \\
\text { bir proaktif kriz yönetim } \\
\text { planı ve pazarlama ileti- } \\
\text { şimine yönelik reaktif } \\
\text { kriz iletişim planı }\end{array}$ \\
\hline $\begin{array}{l}\text { Kriz } \quad \text { İletişim } \\
\text { Ekibi }\end{array}$ & $\begin{array}{l}\text { AVM yöneticisi, güvenlik } \\
\text { müdürü ve kurumsal iletişim } \\
\text { sorumlusu }\end{array}$ & $\begin{array}{l}\text { Genel müdür, operasyon } \\
\text { direktörleri, yönetici ve su- } \\
\text { pervizörleri, pazarlama } \\
\text { ekibi }\end{array}$ & $\begin{array}{l}\text { Kurumsal iletişim, pa- } \\
\text { zarlama ekibi, işletme, } \\
\text { teknik ve bilgi işlem }\end{array}$ \\
\hline Kriz Sözcüsü & Yatırımc1 - kurum yönetimi & $\begin{array}{l}\text { Sessiz kalma stratejisi, Za- } \\
\text { ruri bir durumda Ajans } \\
\text { Açıklaması }\end{array}$ & - \\
\hline $\begin{array}{l}\text { Kriz İletişiminde } \\
\text { Zaman Tablosu }\end{array}$ & $\begin{array}{l}\text { Kriz yönetimi gereği en te- } \\
\text { mel anlamda bir iletişim } \\
\text { akışı }\end{array}$ & $\begin{array}{l}\text { Kriz iletişim zaman tablosu } \\
\text { uygulanıyor }\end{array}$ & - \\
\hline $\begin{array}{l}\text { Kriz İletişiminde } \\
\text { Kullanılan İleti- } \\
\text { şim Araçları }\end{array}$ & $\begin{array}{l}\text { Bilgi İletişim Formu, What- } \\
\text { sApp uygulaması, Email, } \\
\text { Telefon }\end{array}$ & $\begin{array}{l}\text { Yüz yüze iletişim, Email, } \\
\text { sosyal medya uygulama- } \\
\text { ları, yazılı ve görsel basın }\end{array}$ & $\begin{array}{l}\text { Web sayfası, sosyal } \\
\text { medya uygulamaları, ya- } \\
\text { z1lı ve görsel basın ve di- } \\
\text { gerleri }\end{array}$ \\
\hline $\begin{array}{l}\text { Mağdurlarla İleti- } \\
\text { şim }\end{array}$ & $\begin{array}{l}\text { Yüz yüze iletişim, maddi } \\
\text { manevi ihtiyaçları karşılama }\end{array}$ & Yüz yüze iletişim & $\begin{array}{l}\text { Büyük krizler yaşan- } \\
\text { madı }\end{array}$ \\
\hline $\begin{array}{l}\text { Çalışanlarla İleti- } \\
\text { şim }\end{array}$ & E-mail, WhatsApp & $\begin{array}{l}\text { E-mail, Facebook, Twitter, } \\
\text { Instagram uygulamaları }\end{array}$ & E- mail \\
\hline $\begin{array}{l}\text { Ziyaretçilerle İle- } \\
\text { tişim }\end{array}$ & Anons ve duyurular & $\begin{array}{l}\text { Yüz yüze iletişim, Anons } \\
\text { ve duyurular }\end{array}$ & Görsel ve işitsel araçlar \\
\hline Medya İle İletişim & $\begin{array}{l}\text { Kurumsal iletişim uzmanı, } \\
\text { ajans aracıllı̆̆yla iletişim }\end{array}$ & $\begin{array}{l}\text { Kurumsal iletişim, } \\
\text { ajansı desteği }\end{array}$ & $\begin{array}{l}\text { Creative ve Ajans des- } \\
\text { teği, ikili ilişkiler, pazar- } \\
\text { lama departmanı }\end{array}$ \\
\hline $\begin{array}{l}\text { Kriz İletişim Büt- } \\
\text { çesi }\end{array}$ & $\begin{array}{l}\text { Kriz durumları için kulla- } \\
\text { nıma açık bütçe var. }\end{array}$ & Kriz iletişim bütçesi var. & Krize özel bir bütçe yok. \\
\hline
\end{tabular}


Kuşay, Y. (2017). The communication strategies of shopping centers in proactive and reactive crisis communication. International Journal of Social Sciences and Education Research, 3(2), 379-396.

Tablo 2. Kriz iletişiminde ileti içerik özelliği ve iletilen araç

\begin{tabular}{|l|l|l|l|}
\hline \multicolumn{4}{|c|}{ Kriz iletişiminde ileti içerik özelliği ve iletilen araç } \\
\hline \multicolumn{1}{|c|}{ AVM1 } & \multicolumn{1}{|c|}{ AVM2 } & \multicolumn{1}{c|}{ AVM3 } \\
\hline Krize Sahip Çıkma & Olayı yansıtmama eğilimi & Sessizlik politikası & - \\
\hline $\begin{array}{l}\text { Açıklama Yapma \& Özür } \\
\text { dileme }\end{array}$ & $\begin{array}{l}\text { Açıklama ve özür tarzı bir } \\
\text { ileti söz konusu değil }\end{array}$ & $\begin{array}{l}\text { Mecbur kalındığı du- } \\
\text { rumlarda açıklama \& } \\
\text { Özür durumu yok }\end{array}$ & Açıklama var \\
\hline Çift Yönlülük & $\begin{array}{l}\text { Çalışanlar ve diğer pay- } \\
\text { daşlarla çift, diğer ziyaret- } \\
\text { çilere yönelik daha çok } \\
\text { tek yönlü iletişim }\end{array}$ & $\begin{array}{l}\text { Tek yönlü bir ileti- } \\
\text { şim anlayışı }\end{array}$ & - \\
\hline $\begin{array}{l}\text { Şeffaflık } \\
\text { Aynı Mesajın Kurumun } \\
\text { Tüm İletişim Kanalında Yer } \\
\text { Alması }\end{array}$ & $\begin{array}{l}\text { Sadece kendi iç yapısı } \\
\text { içerisinde şeffaflı esas } \\
\text { Möz konusu ise }\end{array}$ & $\begin{array}{l}\text { Kendi bünyesi içeri- } \\
\text { sinde şeffaflık esas }\end{array}$ & $\begin{array}{l}\text { Mesaj paylaşımı ye- } \\
\text { rine, özellikle sosyal } \\
\text { medya takibi }\end{array}$ \\
\hline $\begin{array}{l}\text { Sorulan Soruları Aynı İleti- } \\
\text { şim Kanalı Üzerinden Ce- } \\
\text { vaplanması }\end{array}$ & $\begin{array}{l}\text { Mesaj iletme zorunluluğu } \\
\text { söz konusu ise }\end{array}$ & Evet & Evet \\
\hline
\end{tabular}

\subsection{AVM1}

AVM yönetiminin kriz yönetimi ve kriz iletişim planı sorgulandığında AVM'nin operasyonel ve fiziksel şartlarına bağlı olarak risk analizleri doğrultusunda her zaman ve her durum için bir A, $\mathrm{B}$ ve C planlarının olduğu, bu planların yürütülmesinde proaktif kriz yönetimi anlayışının benimsendiği ifade edilmiştir. Kriz iletişimi noktasında ancak kriz sırası ve sonrasında stratejik bir reaktif kriz iletişimi yürüttükleri tespit edilmiştir. Önceden planlanan ya da revize edilen bir kriz iletişim planından bahsedilmemiştir.

Kriz iletişim ekibi güvenlik müdürü, AVM yöneticisi yani AVM yatırımcısı ve kurumsal iletişim sorumlusundan oluşmaktadır. Güvenlik biriminden alınan bilgiler doğrultusunda kriz iletişim sorumlusu ve AVM yöneticileri hedef kitleler ile nasıl iletişime geçeceklerine yön vermektedir. Daha büyük sansasyonel krizlerde kriz iletişim ekibine ajans dahil edilmektedir.

Kriz iletişim sözcüsü olarak AVM yöneticileri ya da kurumsal iletişim sorumlusu görev almaktadır. Kriz iletişiminde zaman tablosu krizin başlaması ile yönlendirilmektedir. Yaşanılan olayın doğasına uygun olarak kriz iletişim süreci yürütülmektedir. Bilgi iletişim formları üzerinden olan vakalar AVM yönetimlerine maille ulaştırılmakta ya da AVM müdürü, satış ve pazarlama müdürü, idari işler müdürü gibi üst yöneticiler Whats App uygulaması üzerinden ilk kriz iletişim sürecini başlatmaktadır. Daha sonra krizin boyutuna ve şekline göre hedef kitleler ile iletişime yön verilmektedir.

Kriz iletişiminde kullanılan iletişim araçlarının başını bilgi iletişim formları oluşturmaktadır. Krizin yapısına ve olduğu zamana göre Whats App uygulaması, e-mail ya da telefon kullanılmaktadır. Sosyal medya takipleri, talep ve şikayetler kurumsal iletişim biriminin kontrolündedir. Medya takibi kurum içerisinden yürütülmektedir.

Hedef kitleler göz önünde bulundurulduğunda ise; mağdurlarla yakından ilgilenilmekte, AVM içerisinde yüz yüze iletişim kurulmaktadır. Her türlü maddi ve manevi ihtiyaçları karşılanacak şekilde hareket edilmektedir. Ayrıca yasal hakları kendilerine hatırlatılmaktadır. AVM yönetimi kapsamında iletişim, Whats App ağırlıklı sağlanırken, diğer iç hedef kitleler ile, AVM danışmanı arac1lığıyla mağazalarla mail yolu ile iletişim sağlanmaktadır. Kriz anında AVM içerisinde yaşanılan 
Kuşay, Y. (2017). Proaktif ve reaktif kriz iletişiminde alışveriş merkezlerinin iletişim stratejileri. International Journal of Social Sciences and Education Research, 3(2), 379-396.

bir durumda ise ziyaretçilere anons ve duyurular ile iletişim kurulmaktadır. Bunun dışında daha fazla bir açıklama yapılmamaktadır. Olay esnasında kesinlikle basın AVM içerisine alınmamaktadır. Medya ile iletişimde ajans desteği alınmaktadır. Hatta şahsi ikili ilişkilerle medya ile bağlantıya geçilmektedir. Gerek AVM yatırımcısının gerekse güvenlik desteği veren firmanın kullanıma açık bir kriz bütçesi söz konusudur.

AVM1 yönetiminin kriz iletişiminde ileti içerik özelliği ve iletim şekli Tablo 2'de ifade edilmiştir. Kriz durumlarında krize sahip çıkma düşüncesinden ziyade, krizi yansıtmama eğilimi ağır basmaktadır. Kriz olabildiğince minimize edilmeye hatta yok sayılmaya çalışılmaktadır. Dolayısıyla krizle ilgili, açıklama yapma tercih edilmemektedir. Hedef kitlelerle iletişimde genelde çalışanlarla ilgili süreçte çift yönlü, ziyaretçi ve potansiyel hedef kitlelere yönelik ise tek yönlü iletişim izlenmektedir. Medya ile iletişimde ise ikili ilişkilerle ikna içerikli bir iletişim süreci yürütülmektedir. Mesajların şeffaflık ilkesi ile aktarımında iç hedef kitle açısından daha gerçekçi olduğu gözlenmektedir. Karşılıklı iletişim sürecinde, hedef kitlelere bir açıklama yapmak zorunluluğu söz konusu ise mesajın bütün iletişim araçlarında ya da sorulan bir soru söz konusu ise aynı iletişim aracı üzerinden mesajın aktarımının sağlandığı yönünde bilgi edinilmiştir.

\subsection{AVM2}

AVM2 krize yönelik bir kriz yönetim planının olduğunu belirtmiştir. Kriz planlarının operasyon birimi tarafindan acil durum planları olarak hazırlandığı hatta en ileri boyutta en küçük riskleri bile içinde barındırabilecek detaylı kriz planlarının olduğu ifade edilmiştir. Dolayısıyla AVM'nin doğasına uygun olarak olası kriz yönetim planları proaktif olarak mevcuttur. Kriz iletişimi konusunda ise AVM yatırımcısının özel politikası olarak sessiz kalma stratejisi izlediklerini dile getirilmiştir. Dolayısıyla proaktif bir kriz yönetimi içerisinde tepkisiz kalacak bir iletişim stratejilerinin olduğu ancak zaruri bir durumda reaktif bir iletişim planına göre hareket edildiği gözlenmiştir.

Kriz iletişim ekibinde AVM genel müdürü, operasyon direktörleri, yöneticileri ve süpervizörleri ile pazarlama sorumlusundan oluşan 6-7 kişilik bir grup yer almaktadır. Kriz iletişim sözcüsü AVM2 yatırımcısının sessiz kalma stratejisi gereği kurum içerisinden değil, özellikle kriz durumlarında destek alınan PR ve dijital ajanslar aracılığıyla yapılan sözlü açıklamalar ile gerçekleşmektedir. $\mathrm{Bu}$ durumların belirleyici unsurları ise medya takibi sonrasında elde edilen bilgilerdir. Yazılı bir iletişim tercih edilmemektedir. AVM yönetimi ile iletişim kurulmak istendiğinde genellikle medya ajansa yönlendirilirken, bireysel hedef kitlelerle iletişim konusunda ise herhangi bir hata yapılmaması ve farklı bir dil kullanılmaması için çalışanlara, güvenlik görevlilerine iletişim eğitimi verilmektedir. Medya eğitimi başlı̆̆ altında bu eğitimler sürdürülmektedir.

Kriz iletişimde zaman tablosu oluşturmaktan ziyade kriz sırası ve sonrası pazarlama ve satış ekibi deneyim ve tecrübelerden yola çıkarak hareket etmektedir. Önceki krizler bu noktada yol gösterici rehber görevi sergilemektedir. Kriz iletişiminde kullanılan iletişim araçları kriteri açısından bakıldığında sözlü iletişimin kurum politikası gereği öncelik taşıdığı ortaya konmuştur. Bunun d1şında esas önem verilen iletişim ortamı sosyal medya ağlarıdır. Facebook ve Twitter üzerinden iletişim kurulmaktadır. Ancak mecbur olmadıkça sessiz kalmayı tercih etmektedirler.

Hedef kitlelerle iletişimde Facebook ve Twitter önem taşımaktadır. Ziyaretçilere anons ve duyurular ile iletişim kurulmaktadır. AVM mağazaları ile olan iletişim daha çok e-mail ve telefon ile gerçekleşmektedir. Bunun dışındaki durumlarda dijital medya ve PR ajansı sözlü bir şekilde medya ile iletişim kurmaktadır. Kriz sırasında yönetim olarak ortamı gözlemlemek ve görüntü alınmasını 
Kuşay, Y. (2017). The communication strategies of shopping centers in proactive and reactive crisis communication. International Journal of Social Sciences and Education Research, 3(2), 379-396.

önlemek için AVM2 yönetim çalışanlarından bir kaç kişi olayın gerçekleştiği yere yönlendirilmektedir. Böylece kriz esnasında gizli müşteri gibi ziyaretçilerin arasına girip olay yerinde görüntü alınması engellenmeye çalışılmaktadır. Sosyal medyaya bilgi akışını kontrol etmek, ters davranışları anında önlemeye ve gözlemlemeye yönelik o anlık durum tespiti yapılmakta, krizlerin bazen de müşterilerden ziyade mağaza çalışanlarının sosyal medya paylaşımları ile gündeme taşındığı düşünülmektedir. Gazete ve haber ajansları bilgiyi daha çok sosyal medyadan gelen bilgiler üzerinden sağlayabilmekte, bu yüzden mağaza çalışanlarının hesapları kriz anında öncelikle takip edilmektedir. PR ajansı aracılığıyla yazılı açıklama yapılamadığından sözlü olarak medyaya ulaşılmaya çalışlmaktadır.

Kriz iletişim bütçesi olarak kriz planları için hazırlanan bütçeden yararlanılmaktadır "Kriz iletişiminde iletinin içerik özelliği ve iletim şekli nasıldır?" sorusunun verilen yanıtta, krize sahip çıkmada krizin varlığına ve kabulüne yönelik açıklamaların, ülkenin gündemine göre değişiklik gösterdiği belirtilmiştir. Unutulma olasıllğının yüksek olduğu, ülke gündeminin yoğun olduğu dönemlerde sessiz kalma politikası izlenmektedir. "Ne kadar az haber o kadar az kriz" mantığı benimsenmiştir. Pazarlama sorumlusunun belirttiğine göre halk yaşanılan krizleri olumsuzlukları artık eskisi kadar önemsemiyor ya da çok daha çabuk unutuyor. Yani üç sene önceki panik ya da hassasiyet artık yok. Kriz durumlarında dijital ajanslardan "monitoring" hizmeti satın alınmaktadır. Medya izleme ölçümlerine göre hareket edilmektedir. Dolayısıyla aşırı bir hassasiyet ya da yanlış anlama var ise açıklama yapma ihtiyacı hissedilmektedir.

Çalışanlar arasında bilgilendirme sistemi içerisinde şeffaflık esas iken, dış hedef kitle konusunda sessiz kalma politikası hakimdir. Ayrıca çift yönlü bir iletişim akışı söz konusu değildir. Özellikle emniyeti ilgilendiren kriz durumlarında polis raporu olmadan açıklama yapılamıyor. Böyle durumlarda zaman kaybı yahut erken haber akışı bazen yanlış haberlerin ortaya çıkmasına neden olabiliyor. Böyle durumlarda sözlü olarak mutlaka bilgi akışı sağlanmaktadır.

Sosyal medya üzerinden bireysel yorumlara cevap vermenin çok riskli olduğu düşünülmektedir. AVM yönetimine sözlü olarak ulaşıldığında herkese cevap vermeye çalışıldığı belirtilmektedir. $O$ yüzden tek ağızdan konuşabilmek ve özellikle basından biri aradığında mesajın çarpıtılmaması için AVM2 yönetim çalışanlarına medya eğitimi verilmektedir. Ayrıca bu eğitim mağaza içi çalışan danışma ve güvenlik personeli için de geçerlidir.

\section{3. $A V M 3$}

AVM3 yetkilileri, alışveriş merkezinin fiziksel şartlarına göre proaktif kriz yönetim planına sahip olduğunu ve reaktif bir kriz iletişimi planı doğrultusunda hareket edebileceklerini, ancak şimdilik ciddi bir kriz ile karşılaşmadıklarını ifade etmişlerdir. Kriz iletişim ekibinde kurumsal iletişim sorumlusu, pazarlama ekibi, işletme, teknik ve bilgi işlem yetkililerinin yer alabileceği belirtilmiştir. Henüz ciddi bir kriz deneyimleri olmadığı için kriz sözcüsünün kim olacağının planlanmadığına değinilmiştir.

Kriz iletişiminde zaman tablosu AVM3 yönetimi için söz konusu değildir. Kriz iletişiminde kullanılan iletişim araçları, kriz durumlarında creative ve PR ajansından alınacak destek ve medya ile yürütülecek ikili ilişkiler çerçevesinde belirlenmektedir. Kurum içinde bu anlamda pazarlama departmanı ajans ile birlikte çalışmaktadır. Bunun dışında web sayfası, sosyal medya ağları, anons ve duyurulardan faydalanılmaktadır. 
Kuşay, Y. (2017). Proaktif ve reaktif kriz iletişiminde alışveriş merkezlerinin iletişim stratejileri. International Journal of Social Sciences and Education Research, 3(2), 379-396.

Hedef kitlelerle iletişimde Web sayfası, Facebook ve Twitter uygulamaları küçük çaplı yaşanılan krizler için en sık kullanılan iletişim araçlarındandır. Bu ortamlar ziyaretçi ve müşterilere ulaşmak için kullanılmaktadır. Medya ile iletişimde ikili ilişkiler ağılık basmaktadır. Kurumun kriz iletişim bütçesi yoktur. Kriz iletişiminde ileti içerik özelliği ve iletim şekli değerlendirildiğinde, AVM3'ün kriz konusundaki deneyim ve tecrübelerinin yoğun olmaması nedeniyle, kriz yönetim planından öteye geçememiş olduğu gözlenmiştir. Dolayısıyla kriz sırası ve sonrasında mesaj içerik özellikleri başlı̆̆ altında tanımlanan krize sahip çıkma, özür dileme, mesajın çift yönlü olması, şeffaflık ilkeleri soruları cevapsız bırakılmıştır. Önemli durumlarda açıklama yapma ihtiyacı hissedildiği ifade edilmiştir. Bu da etkinlik iptali duyurusu niteliğinde daha basit içeriklerden oluşmaktadır. Krizde sosyal medya takibi ile tepkilerin ölçümlendiğini belirtilmiştir.

\section{Araştırmanın değerlendirilmesi}

Kriz Öncesi İletişim: Araştırmadan elde edilen bulgular doğrultusunda, alışveriş merkezlerinin yapılarına, lokasyonlarına ve hedef kitle profillerine özgün, olası kriz yönetim planlarının olduğu tespit edilmiştir. Kriz yönetim planlarının oluşturulmasında yapılan risk analizlerinin önemli yer kapladığı gözlemlenmiştir. Kriz yönetim planları alışveriş merkezi güvenlik birimleri tarafından AVM yöneticileri ile hazırlanmaktadır. Kriz yönetim planlarının içeriği genelde olası kriz risklerine yönelik; hırsızlık, güvenlik zafiyeti, yangın, elektrik kesintisi gibi konular üzerine yoğunlaşmaktadır. Proaktif kriz yönetimleri içerisinde kriz iletişiminin reaktif olarak kriz sırası ve sonrasında uygulamada yerini aldığı tespit edilmiştir. Araştırma kapsamında kriz öncesi başlatılan proaktif kriz iletişim stratejisini uygulayan bir AVM örneği bulunmamaktadır.

Kriz Sırası İletişim: Kriz yönetim sürecinde söz sahibi olan AVM güvenlik birimleri ve yönetimleri kriz sırası ve sonrasında iletişimi; kurumsal iletişim departmanı ile pazarlama ve satış departmanlarının sorumluluğuna ve ajans yetkililerine bırakmaktadır. Yine de kriz yönetim ekibinin ilişkilerine göre kriz iletişiminin yönlendirildiğini söyleyebiliriz.

Alışveriş merkezlerinin kriz durumlarında açıklama yapma, durumu şeffaflıkla dile getirme ya da çift yönlü iletişim kurmada daha kapalı bir iletişim stratejisi izlediği gözlenmiştir. Alışveriş merkezleri, kriz iletişimini ne kadar az bilgi, o kadar az risk ve kriz mantığı üzerinden yürütmektedir.

Kriz sırası ve sonrasında yapılan medya izlemeleri de (monitoring) iletişim sürecinin belirleyici noktasını oluşturmaktadır. Medya takibi, gerek çalışan paylaşımları, gerekse medya ve hedef kitle paylaşımları açısından önem taşımaktadır. Kurum içinden yahut PR ajansları ve dijital ajanslardan aldıkları monitoring (izleme) hizmetleri ile medya takibi mutlaka yapılmaktadır. Kriz iletişiminde belirlenecek olan strateji, ülkenin gündem yoğunluğuna ve halkın verdiği reaksiyonlara göre medya ve diğer hedef kitle ile kurulacak mesaj içeriğini belirleyebilmektedir. Bu noktada bazen sessiz kalma politikasının devamlılığı, bazen medya ile ikili ilişkiler bazen, üçüncü ağızlardan bilimsel destek alma ya da sosyal medya üzerinden iletişime geçme gibi uygulamaların tercih edildiği tespit edilmiştir. AVM yönetimindeki çalışanlar ve mağaza çalışanları ile olan iletişimde ise daha yoğun ve açıklayıcı bir iletişim tercih edilmektedir.

Kriz Sonrası İletişim: Alışveriş merkezleri proaktif kriz iletişimi için pek bir şey yapmıyor olsalar da onlar için önemli olan hedef kitlenin nabzını her zaman ölçmektir. Kriz sonrası süreç de bunlardan biridir. Kriz sonrası yapılan medya takipleri ile etki ölçümü amaçlanmaktadır. Elde edilen veriler ve yaşanılan deneyimler gelecek dönemler için örnek teşkil etmektedir. AVM ilgili birimleri, bu argümanlardan yola çıkarak yazılı olmayan bir kriz iletişim sürecini, olası krizler 
Kuşay, Y. (2017). The communication strategies of shopping centers in proactive and reactive crisis communication. International Journal of Social Sciences and Education Research, 3(2), 379-396.

için yapılması gerekenler olarak değerlendirmektedirler. Bunun dışında kriz iletişimi sonrasında krize yönelik pek bir çalışma yapılmadığı gözlenmiştir.

\section{Sonuç ve tartışma}

Medyaya yansıyan olumsuz haberler alışveriş merkezlerinin güvenliği konusunda halkı tedirgin etmektedir. Bu durum mimari açıdan pek çok mağazayı ve etkinliği bir araya toplayan alıveriş merkezlerinin imajını da olumsuz yönde etkilemektedir. Çalışma kapsamında güvenlik konusunun yanı sıra farklı sebeplerle alışveriş merkezlerinde yaşanılan krizlere, AVM yönetimlerinin yaklaşımı kriz iletişim stratejileri açısından değerlendirilmiştir. Elde edilen bulgulardan ve araştırma sonuçlarından yola çıkarak; alışveriş merkezlerinin fiziksel şartlarına yönelik, operasyonel anlamda pek çok olasılığı içeren proaktif kriz yönetim planları kurgulamalarına karşın, kriz iletişimi konusunda yeterli olmadıkları tespit edilmiştir. Krizin ortaya çıkması ile birlikte yürütülen reaktif bir kriz iletişim planının benimsendiği gözlenmiştir. AVM yönetimleri yaşanılan kriz durumlarını medyadan olabildiğince uzak durarak kendi içlerinde çözmeyi tercih etmektedirler. AVM yönetimleri için medya ile kurulacak her bir ilişki, sonrasında farklı algıların yansıtılabileceği ve aleyhte işleyebilecek bir süreç olarak yorumlanmaktadır. Bu düşüncenin nedeni medya ile karşılıklı ilişkilerde reklam verme, ropörtaj yapma, finansal değerlerin paylaşımı söz konusu ise lehte bir medya yansıması olacağı görüşüdür. Medya ile ilişkilerde karşılıklı bir çıkarın söz konusu olmadığı durumlarda aleyhte haberlerin artacağı düşünülmektedir. Bu durum AVM'lerin iletişim stratejileri ile doğru orantılıdır. AVM ve medya arasında bahsedilen anlamda karşılıklı bir ilişki söz konusu ise, AVM'nin olumsuz haberlerinin önüne ikili ilişkilerle geçilebileceği anlayışı hakimdir. Bu noktada medya ile ilişkisi olmayan AVM'ler PR ve dijital ajansların desteğini alarak kriz iletişim süreçlerini, kriz sırası ve sonrasında yürüttüklerini belirtmektedir. AVM yönetimlerinin kriz iletişimi konusundaki genel kanıları sessizlik politikası üzerine oturmaktadır. Hedef kitlelere yönelik kriz sürecinde yapılacak olan sosyal medya paylaşımlarının, kötü niyetle değerlendirilebileceği ve olayın daha da büyümesine neden olacağı görüşü hakimdir. Bu yüzden minimum düzeyde bilgi akışı benimsenmektedir. Çift yönlü bir iletişimden bahsetmek pek mümkün görünmemektedir. Buna karşın, hedef kitlelerin tepkilerinin ölçümlenmesi adına, kriz sırası ve sonrasında gerek kurum içi gerekse ajans desteği ile sosyal medya izlemeleri ciddi bir şekilde yürütülmektedir.

AVM yönetimlerinin, kriz iletişim stratejilerini krizin ortaya çıkmaya başladığı andan itibaren reaktif olarak yürütüldüğü tespit edilmiştir. Kurumsal iletişim sorumlusu, pazarlama ve satış birimi, AVM yöneticisi, güvenlik birimleri, teknik birim gibi krizle bağlantısı olabilecek birimlerin ortak söz sahibi olduğu kriz iletişim ekipleri oluşturup, kriz iletişim planı çerçevesinde hareket etmektedir. Kurum sözcüsü her AVM'nin kendi politikasına göre değişkenlik arz etmektedir. Kurumsal iletişim sözcüsü, AVM yönetimi, PR ajansları kriz sözcüsü görevini üstlenebilirken, bazen de sessizlik politikası güdülmektedir. Kriz iletişiminde yapılacak işlerin zaman tablosu, genellikle önceki deneyim ve tecrübeler, kriz yönetim planı çerçevesinde yapılacak işlerin akışına göre de yönlendirilmektedir. Bu anlamda tam bir çerçevenin çizilmediği görülmektedir. Kriz iletişiminde hedef kitlelerle iletişim konusu yine AVM yönetimlerinin uzak durmaya çalıştığı uygulamalardan biri olarak görülmektedir. Hedef kitlelerle kurulacak iletişimin krizlerin büyümesi ya da daha da belirginleşmesi konusunda büyük bir risk olduğu görüşü ortaya çıkmaktadır. Bu durum kriz iletişiminde iletişim araçlarının kullanımı için de geçerlidir. AVM yönetim anlayışına göre sosyal medya ya da diğer iletişim araçlarının kullanımı minimum seviyede tutulmaya çalışılmaktadır. 
Kuşay, Y. (2017). Proaktif ve reaktif kriz iletişiminde alışveriş merkezlerinin iletişim stratejileri. International Journal of Social Sciences and Education Research, 3(2), 379-396.

Mesajların içerikleri genellikle tek taraflı sunulmakta hatta mümkün ise krize yönelik bir paylaşımda bulunulmamaya çalışılmaktadır.

Sonuç olarak AVM yönetimlerinin izledikleri bu stratejiler, hedef kitlelerin, toplumsal bir tehdit olduğunda, ya da AVM'ler ile ilgili olumsuz bir haber yansıdığında, oluşan algıları değiştirmeye ya da tedirginliklerini gidermeye yetmemektedir. Hedef kitleler ile kurulacak daha aktif bir iletişim anlayışının, bir tehdit oluşturabileceği ve sosyal medyanın bu anlamda körükleyici bir zemin olduğu fikrinin değiştirilmesi gerekmektedir. Bunun için en baştan planlanacak ve defalarca revize edilebilecek bir proaktif kriz iletişim anlayışı, AVM yönetimlerinin, hedef kitlelerini daha iyi analiz etmelerini, doğru zamanda ve doğru iletişim kanalı ile etkili mesajların sunulmasına imkan tanıyacaktır. Kriz yönetim planına entegre edilen bir kriz iletişim planı stratejisinin mutlak surette hazırlanması gerektiği AVM'lere önerilmektedir. Böylelikle hedef kitlelerle iletişimde yanlış anlaşılmaların önüne geçilerek, kriz öncesi, sırası ve sonrasında AVM'lerin kendilerini en iyi şekilde ifade edebilmeleri sağlanmış olacaktır.

\section{Kaynakça}

Akbayir, Z., Kuşay, Y., (2015, Oct. 29-31). "Sosyal Medyadan Krize Bakış: Otomotiv Sektöründe Kriz Dönemlerinde Sosyal Medyanın Kullanımına İlişsin Bir Araştırma", International Conference on Social Sciences and Education Research, Antalya, Türkiye, 1177-1193.

Benoit, L. W.(1997). Image Repair Discourse and Crisis Communication, Public Relations Review, 23(2): 177-184.

Bernstein, J., "The 10 Steps of Crisis Communications" (http://www.bernsteincrisismanagement.com/the10-steps-of-crisis-communications/, 21.10.2016)

Craig, M., Olaniran, A. B., Scholl, C. J., Williams, E. D., (2006, June). "Crisis communication in public arenas" Public Relations Review, Elsevier, 32(2), 171-173.

Coombs, W. T., (2007). Ongoing crisis communication: Planning, managing and responding (2nd ed.). Thousand Oaks, CA: Sage.

Coombs, W. T., \& Holladay, S. J. (2002). Helping crisis managers protect reputational assets: Initial tests of the situational crisis communication theory. Management Communication Quarterly, 16, 165-186.

Coombs, W. T., \& Holladay, S. J. (2008). Comparing apology to equivalent crisis response strategies: Clarifying apology's role and value in crisis communication. Public Relations Review, 34, 252-257. doi: 10.1016=j.pubrev.2008.04.001

Ford. L. J., Ford, S. J., Frei, S.S., Pilny A., \& Berkelaar L. B., (2016). A network under stress: using embeddedness to understand uncertainty management and resilience in campus emergencies, Journal of Applied Communication Research, 44:3, 316-335, DOI: 10.1080/00909882.2016.1192288

Hale, E. J., Dulek, R. E., \& Hale, D. P., (2005). Crisis response communication challenges- Building theory from qualitative data. Journal of Business Communication, 42(2), 112-134.

Kiambi M.D. \& Shafer, A., (2016). Corporate Crisis Communication: Examining the Interplay of Reputation and Crisis Response Strategies, Mass Communication and Society, 19(2), 127-148, DOI: $10.1080 / 15205436.2015 .1066013$

Kim, S., Avery, E. J., \& Lariscy, R. W., (2009). Are crisis communicators practicing what we preach? An evaluation of crisis response strategy analyzed inpublic relations research from 1991 to 2009. Public Relations Review, 35, 446-448. 
Kuşay, Y. (2017). The communication strategies of shopping centers in proactive and reactive crisis communication. International Journal of Social Sciences and Education Research, 3(2), 379-396.

Liu, F.B. \& Bartz, L., \& Duke, N., (2016). Review Communicating crisis uncertainty: A review of the knowledge gaps, Public Relations Review, 42, 479-487.

Loosemore, M. (1998). The three ironies of crisis management in construction projects. International Journal of Project Management, 16(3), 139-144.

Reynolds, B., \& Seeger, M. W., (2005). Crisis and emergency risk communication as an integrative model. Journal of Health Communication, 10(1), 43- 455. http://dx.doi.org/10.1080/10810730590904571Robinson

Seyfi, M., \& Güven, D., (Oct. 2016). The Perception and Awareness Levels of University Students in Turkey Regarding Crisis Situations in Social Media: The University of Marmara Example. Athens Journal of Mass Media and Communications, Vol. 2, No. 4, 269-280.

Stoff, R., (2007, September). Crisis in Communications, St Louis Journalism Review, , 20-21.

Van Der Meer, G.L.A. T., Verhoeven, W.M. J., (2014). Emotional crisis communication, Public Relations Review, 40, 526-536.

Whitt, C. M., (2014). Building A Proactive Crisis Communications Program, University Business, 17(11), p.22.

Ying, Z., Pheng, S. L., (2014). Project Communication Management in Complex Environments, Springer Science\&Business Media, Singapore.

\section{Extended Abstract in English}

Purpose and Significance: As the social living spaces, the shopping centers are the main intensively visited places during the daily life. The negative news such as bomb warnings, suicides, robbery and so on may throw doubt on perceptions of stakeholders, regarding the security and shopping centers and etc. It also damages their image and reputation. The purpose of this study is to identify the proactive and reactive crisis communication strategies of shopping center managements against such cases that lead adverse impacts on the stakeholders. The importance of this study would be identifying the strengths and weaknesses of communication strategies of shopping centers within the scope of crisis communication.

Literature: Crisis is defined the perception of an unpredictable regarding health, security, environment, economic problems that threatens important expectancies of stakeholders and can seriously impact an organization's performance and generate negative outcomes. (Coombs, 2007: 3). All actions that have previously been taken with the purpose of either prevention from crisis or overcoming the crisis with a minimum level of damage and turning the crisis into opportunities in some cases are assessed within the process of crisis management process. However, the operational crisis management strategies do not always match with the communicational aspects. The lack of a crisis communication system may have negative impacts on the planned crisis management processes.

Coombs \& Holladay (2002) define crisis communication as the information that helps stakeholders understand the situation. The strategies developed for the communicational crisis may either improve the corporate image or prevent the loss of reputation by combining benefits from experiences and the ideas of stakeholders (Van der Meer and Verhoeven, 2014: 527). The impressive public relationship specialists adopt a proactive crisis communication system whereas the crisis communication plan mainly applies in line with the reactive remedies. For the proactive crisis communication plan, communication with corporation manager and other related managers 
Kuşay, Y. (2017). Proaktif ve reaktif kriz iletişiminde alışveriş merkezlerinin iletişim stratejileri. International Journal of Social Sciences and Education Research, 3(2), 379-396.

requires a prepared communication plan covering the following aspects: setting up a strong relationship with media, following up potentially existing situation, considering and caring of crisis, developing skills for crisis management, reconsidering the crisis communication plan and following up the results of crisis after a crisis (Whitt, 2014: 22). On the other hand, reactive crisis communication refers to communication process to be performed during and after a crisis, when the crisis arises unexpectedly, there exists no defined pre-crisis communicational strategy.

Jonathan Bernstein defined the crisis communication criteria so as to minimize the impacts of crisis as follows (Bernstein, 21.10.2016):

1. Foreseeable crisis / Crisis Communication Plan: As a pre-crisis proactive crisis communication, a comprehensive brain storming, which covers all possible crisis, is performed by the involvement of crisis communication team. This process covers both operational and communicational aspects at the same time.

2. Set-up of a Crisis Communication Team: A small high level management team is determined.

3. The Determination of Crisis Spokesperson: The authorized spokespersons make a speech. It is important that the crisis spokespersons are articulate and the written are appropriately prepared and expressed in a clear way.

4. The Education of Crisis Spokesperson / The Use of Stakeholder Communication Tools: A preparation for making the reactions of stakeholders suitable is necessary.

5. The Set-up of Feedback and Monitoring Systems: Information regarding the prevention of crisis and reactions for crisis is collected during the phase. These systems help in understanding the reactions on stakeholders.

6. The Determination of Stakeholder: The internal and external stakeholders of the corporation are determined.

7. Develop a Corporation Statement: The complete contents are prepared related to possible crisis scenarios, before the crisis occurs.

8. The Evaluation of Crisis: In case of a communication plan that is planned based on the nature of crisis in accordance with the information obtained from crisis communication team, a proper response in the short-run is developed.

9. The Definition of Key Messages: The crisis communication team should develop messages specific to crisis in accordance with stakeholders.

10. Post-Crisis Analysis: The crisis communication team performs an analysis of what was wrong during the crisis, how to compensate the impacts of deficiencies and mistakes and how to develop various factors in order to prepare for a more successful crisis communication plan against any possible crisis thereafter.

In case of crisis, the communication with stakeholders (those charged with governance, employees, customers, victims and relatives of victims, media) is essential with the purpose of corporate reputation. The communication tools to be used in the communication with stakeholders and the contents of the messages should be determined consciously. 
Kuşay, Y. (2017). The communication strategies of shopping centers in proactive and reactive crisis communication. International Journal of Social Sciences and Education Research, 3(2), 379-396.

With the purpose of crisis communication, the adoption of a dual and interactive communication approach in the messages, sharing of detailed and both positive and negative information related to crisis, demonstration of a transparent structure, apologizing for negative impacts of crisis or making and overall explanation for the reasons, results and compensation of crisis, owning the crisis and undertaking the compensations for damages, monologism and adopting the same message to each communication channel of corporation represent the constant criteria of crisis communication (Akbayır and Kuşay, 2015: 1181).

Methodology: A literature scanning related to crisis communication and shopping centers has been performed within this study. The research questions prepared in accordance with the data obtained have been addressed to authorities of shopping centers (Security manager of shopping center, operation manager, and corporate communication coordinator). Interviews have been performed with management of a sample of three shopping centers, which have been randomly selected within the province of Istanbul (October 7 -October 28, 2016). The structures of shopping centers selected have been determined by considering their locations and visitor-stakeholder profiles. The names of shopping centers disclosed with the purpose of their confidentiality concerns. Accordingly, the selected shopping centers have been called as SC1, SC2 and SC3.

During the face-to-face interviews performed with the authorities of shopping centers, it was primarily examined whether they have a crisis management plan and have a crisis communication plan with the scope a forementioned management plan. It was also questioned whether they have a preparation for crisis communication. Consequently, it was aimed at understanding whether they consciously carry out a crisis communication for the possible crisis in shopping centers. The main titles of the questions addressed to authorities of shopping centers within the scope of "crisis communication criteria" are covered as follows: "Timetable in Crisis Communication", "The Communication Tools Used in Crisis Communication (with victims, employees, visitors and communication with media), "Crisis Communication Budget". The criteria that were examined in order to identify the contents of messages sent to stakeholders during the crisis communication process and how these messages were sent are as follows: "Owning the Crisis", "Explanation Apologizing", "Dual Structure", "Transparency", "Including the same message in all communication channel".

Results and Conclusion: It has been identified that the shopping centers are not sufficient enough for crisis communication, although they set up proactive crisis management plans including various operational possibilities with respect to physical conditions of shopping centers. It has been observed that they adopt a reactive crisis communication plan against crisis. A crisis communication team including the units have a common saying and interrelated to each other such as corporate communication responsible, sales and marketing unit, shopping center manager, security units and technical units. Corporate spokesperson may vary based on the policies of shopping center. A silence policy is sometimes followed whereas corporate communication spokesperson, shopping center management and PR agencies can be act as a crisis spokesperson. The time table for the tasks crisis communication is generally determined based on past experiences and the flow of tasks to be performed within the framework of crisis management plan. With this respect, it has been observed that a complete framework is not drawn. It has also been observed that the issue of communication with stakeholders during the crisis communication is the one of the practices that shopping center managements avoid. The idea of the fact that communication with stakeholders is a high risk associated with increased risk of communication crisis. This fact is also 
Kuşay, Y. (2017). Proaktif ve reaktif kriz iletişiminde alışveriş merkezlerinin iletişim stratejileri. International Journal of Social Sciences and Education Research, 3(2), 379-396.

valid for the use of communication tools in crisis communication. According to management approach of shopping centers, the use either social media or other communication tools are kept minimum. The content of messages is generally presented one-sided; in fact they avoid sharing no information related to crisis, if possible.

Consequently, these strategies followed by the shopping center managements are not sufficient enough to meet to change the perceptions and concerns of stakeholders arising when there is a publicly threat or a negative news regarding the shopping centers are revealed. The idea that a more active communication approach in communicating with the stakeholders may lead to a threat and the social media may form an instigative basis with respect to this should change. Accordingly, a proactive crisis communication approach associated with a pre-determined plan can serve shopping center managements in assessing the stakeholders and sending the attractive messages in a proper timing and communication channel. The shopping centers are suggested to prepare a strategy for crisis communication plan integrated with crisis management plan. Accordingly, the shopping centers can be in position to express themselves in a best way by avoiding misunderstanding when communicating with stakeholders. 